\title{
Azmapu: uma proposta normativa Mapuche ${ }^{1}$
}

\author{
Martin Cárdenas Llancaman*
}

\section{INTRODUÇÃO}

Distante hoje é a memória de um dia de agosto do ano 2000, quando a casa das irmãs Quintreman foi visitada por um presidente da república ${ }^{2}$. Em resposta à afirmação da autoridade do Estado de que a lei deve ser respeitada para resolver o conflito, Nicolasa Quintreman respondeu "nós respeitamos a lei, os Wigka e ENDESA não respeitam a lei" (Toro, 2002). A situação descrita enquadrada em um dos mais longos conflitos territoriais e ambientais que podem ser lembrados - pode levantar pelo menos dois cenários diferentes: ou a disputa na apreciação do que significa o cumprimento da lei referia-se ao poder (ou falta dele) dos intervenientes; ou foram as próprias noções de "lei" que gravitaram dimensões imensuráveis.

Quero partir do segundo cenário para destacar o problema em que este artigo trabalha: que códigos, linguagens e significados dão forma a uma ideia normativa que é diferente da concepção normativa que foi historicamente realizada no processo de colonialidade/modernidade? Como o hábil leitor pode perceber, esta tentativa teórica não parte da questão se talvez seja possível articular uma história divergente, mas da convicção de que «o pensamento decolonial é o das diversas oposições planetárias ao pensamento único» (Mignolo, 2007: 33). Com este trabalho quero levantar uma dessas variadas oposições; a ideia de uma normatividade territorialmente localizada, e, além disso, que é refletida e vivida a partir do pensamento mapuche. Tendo em conta que «a ideia de direito, a ideia de justiça, reparação, punição, retificação, estão presentes e não graças ao contato com o Ocidente, mas é uma prática que tem acompanhado grupos humanos desde muito antes» (Quidel, 2016: x), apresento neste artigo a noção de azmapu, termo recorrente na linguagem mapuzugun para definir o certo (ou errado) de certas ações. Realizar a reflexão a partir deste lugar - geográfico e epistêmico -

\footnotetext{
* Licenciado en filosofía por la Universidad Alberto Hurtado, Chile. Estudiante de Magíster en filosofía, Universidad de Chile. Santiago de Chile. cardenas.llancaman@gmail.com Texto traduzido do espanhol por Silvana Winckler - silvanaw@unochapeco.edu.br
} 
em particular, é sublinhar o esquema da diferença colonial «dos diversos locais culturais e epistêmicos dos povos colonizados do mundo» (Grosfoguel, 2007: 73).

Embora esta forma de conhecimento específico chamado azmapu apareça no discurso público, por sujeitos mapuches que destacam a sua importância política (Hunchunao, 2016), ou esteja associada a uma forma de ordem que teria sido quebrada com a irrupção do colonialismo (Quidel, 2015), há poucas referências ao significado de $a z m a p u$, à função que cumpre para o povo mapuche ou qual é a sua fonte de legitimidade. Consequentemente, a primeira parte deste texto procura dar conta do que significa azmapu a partir das condições atuais da vida e do pensamento Mapuche. Adianto que azmapu teria pelo menos duas formas de ser entendida, primeiro como representação e ordem de um espaço e, também, como sistema normativo, nas palavras de Melin, Coliqueo, Curihuinca e Royo, como um direito próprio.

Um segundo momento é mostrar a forma como esta normatividade alternativa tem sido relacionada -desde a exclusão - com o sistema de conhecimento representado pela lei ocidental. Explico, se o pensamento Mapuche - que privilegia uma forma de transmissão de conhecimento intergeracional tem ao mesmo tempo clareza sobre o que significa uma forma normativa 'outra', tem de ser possível a continuidade desse pensamento e o traço da sua marca e da sua ferida na história Mapuche. Ao fixar o fato da ocupação militar do território mapuche pelos estados chileno e argentino (por volta de 1880), como ponto inaugural do processo de colonialidade/modernidade, pretendo mostrar como as condições de sua exclusão foram forjadas perante a lei e o direito da nova sociedade colonial e colonizadora. Nesta tentativa, a linguagem e o olhar oferecem - segundo a minha perspectiva - aspectos chave para compreender de forma conceitual a diferença colonial entre a azmapu e a legislação. Nesta secção procurarei também relacionar os problemas da constituição desta problemática relação com as reflexões que emergiram do giro decolonial; a modernidade e a colonialidade podem ser tomadas como ferramentas de análise nesta forma de conhecimento e de ação que nomeio com azmapu.

\section{DAR VOLTA À TERRA: UMA APROXIMAÇÃO A AZMAPU}

Como primeiro trabalho, preparo nesta secção uma definição provisória para a azmapu. O termo no Mapuzugun tem uma longa história na memória mapuche e é frequentemente usado, no entanto, tem sido nos últimos anos que ele "se torna eficaz precisamente nas comunidades mais afetadas pela resposta punitiva do Estado às suas demandas territoriais e a consequente criminalização de seus membros" (Villegas, 2014: 216).

Considerando a última afirmação, o tratamento do azmapu surgiu como parte das reflexões que abrangem o pluralismo jurídico e a antropologia jurídica, com base na experiência política concreta de algumas comunidades. 
Libertar a política é neste sentido um passo fundamental, é reconhecer primeiro que a azmapu inclui uma projeção e afirmação de como as decisões, ações e vida devem ser ordenadas para além do comportamento individual. Esta relação de ordem entre vida, comunidade e território é um primeiro quadro reconhecível na definição procurada:

Bem, os pvllvs fazem justiça igualmente, quando o che não consegue resolvê-la e aqui está um exemplo claro, e isso não tem nada a ver com a wigka, então eu entendo a questão de que em Ragintu lewfv, o AzMapu de ragintu lewfü está apenas sendo ordenado [...] porque isso tem que ser ordenado, tem que haver um gillatun e esse gillatun tem que ter uma forma de acordo com o $A z$ e que, ainda está sendo ordenado. Então AzMapu é um tema que engloba tudo, que abraça tudo e tem diferentes dimensões [...] AzMapu é a forma como a vida se desenvolve num determinado espaço territorial, e que $A z M a p u$ é auto-regulado. É assim que eu entendo isso. Ela se regula em um determinado espaço, como é moldada, esteticamente eu diria a wigka. Essa é a sua imagem $A z$ a sua forma, mas também como a vida se desenvolve, como ou que tipo de novidade existe lá (Ernesto Huenchulaf in Melin et al, 2015: 35).

Esta primeira abordagem aponta alguns tópicos que são importantes para trazer para a frente da nossa reflexão. Uma delas é a ligação com o espaço territorial. Do pensamento mapuche, a pessoa não existe separada ou privada de sua relação com o território. O espaço, além disso, é interpretado a partir da confluência de forças; na citação anterior onde o che, o povo, não pode resolver, $\mathrm{o}$ pvllv são resolvidos, ou seja, forças espirituais que transcendem o humano e que habitam os espaços onde a vida é levada a cabo. É nesse sentido que a experiência comunitária do homem e da mulher, eles são parte de um espaço maior do que aquilo que é materialmente perceptível:

[...] nós, os che, fazemos parte do wall mapu, entendido como a terra em que vivemos, que reúne todos os espaços materiais e imateriais que o compõem, não só o que sentimos debaixo dos nossos pés, mas também o que está acima, abaixo e dentro dele. Em todos estes espaços há newen, ngünen e ngen (Caniullan \& Mellico, 2017: 44).

A representação do espaço tem um lugar especial no que se entende por azmapu e - como já foi lido até agora - a ordem desse espaço representado é tão importante como os elementos que o compõem. Se estivéssemos procurando um ponto de vista para localizar a corporalidade do sujeito mapuche naquele espaço, teríamos que dizer que aquele corpo não está acima do espaço, na atitude do conquistador que se constrói como um conquistador de ego (Dussel, 1996) avançando geograficamente através de um mapa plano e desprovido de forças. 
O ser "debaixo dos pés" é percebido como uma referência relativa, não absoluta, na compreensão de que newen (forças) e ngen (donos do espaço) existem, abaixo e acima desse ponto de contato, dentro dessa referência relativa e, se a estendemos, também pelos lados da sua localização momentânea. Considerar a representação ou imagem (az) do território (mapu) como já ordenada antes do encontro do sujeito com o espaço, não é apenas olhar de forma diferente, é saber que o olhar não constitui o sentido do observado, que o humano e a sua ação requerem "pedir permissão"3 ao espaço e que não o fazer é irromper e intervir. Como Nicolasa Quintreman disse antes da oferta para trocar "suas" terras como resultado do conflito hidrelétrico; "se eles nos tirarem daqui, para onde vamos? Para interromper em outro lugar? (Toro, 2002). Independentemente de qualquer relação de olhar humano, o espaço já é. Longe de qualquer palavra ou reconhecimento humano, na "floresta as árvores se acariciam com suas raízes azuis / e sacodem seus galhos no ar / cumprimentando com pássaros / o Cruzeiro do Sul" (Chihuailaf, 1995, poema A Chave que Ninguém Perdeu).

A noção de ordem e sua associação com o comportamento normativo correto é recorrente quando se fala em azmapu. O azmapu determina um modelo de comportamento esperado, e depois poderíamos dizer que ele é apresentado, com efeito, como um corpo ético-normativo que permite a resolução de conflitos para a comunidade Mapuche. Aqui estão alguns exemplos disto em Azmapu. Uma abordagem ao sistema normativo Mapuche a partir do rakizuam e do próprio direito:

“Azkvlekefuy ta mapu kuyfi em, petu ñi akunun ta pu wigka (a vida mapuche foi ordenada antes da chegada da wigka) porque havia respeito (yamvwkefuy ta che) entre as pessoas e para com toda a vida que existe (ixofillmogen ta ekugekefuy), e se viveu de acordo com os ciclos que apontavam para o sol, a lua e o céu (kallfv wenu) que em wigkazugun chamamos de céu" (Manuel Melin em Melin et al, 2016: 37).

"Como em toda sociedade organizada, na sociedade mapuche havia um sistema de ordem e controle dos comportamentos negativos que tentavam contrariar a ordem estabelecida pela norma sociocultural ou de acordo com o que indicava o mogen AzMapu de cada lof. Quando surgiram tipos de conduta que estavam em desacordo com as normas e de acordo com os casos conhecidos, como regra geral as instâncias de retificação ou sanção eram dadas dentro da família e da comunidade, dependendo do ato ou má conduta que foi cometida” (Victor Antilef, Kimche, in Melin et al, 2015: 35).

É interessante notar que as transgressões ao azmapu são narradas como capazes de serem retificadas pela família e pela comunidade. Azmapu, poderíamos então dizer, não só aponta a perturbação da ordem, mas também inclui um sistema de sanções e comportamentos comunitários que são ativados pela transgressão. Em um estudo específico sobre o sistema de sanções indígenas, é afirmado 
“...independentemente dos fatos cometidos por um peñi ou uma lamgen não há condenação, há sempre uma conversa e que não é acompanhada de prisão, digamos que não prejudica as pessoas como neste caso dos papéis de antecedentes, as pessoas que cometem um erro são acompanhadas por um gülam, o que dizemos sobre aconselhá-lo... digamos, já, você cometeu esse erro, nunca mais o cometa porque somos todos parentes ou de alguma forma tentamos limpar a sua imagem dessa forma" (Lonko de Temulemu, em Villegas, 2014: 232)

Além disso, após Villegas, no caso de pequenas transgressões - mas que podem significar conflitos mais graves no futuro - é considerada a possibilidade de prevenção através de conversas ou mediação por terceiros. No caso de infracções graves, tais como roubo, danos físicos ou materiais, também pode ocorrer e ser considerado legítimo um malon, ou seja, um ataque físico usando violência, entre as duas partes envolvidas ou entre as suas famílias. O isolamento ou exclusão do infrator da comunidade é também uma medida para resolver possíveis conflitos (Villegas, 2014: 228-233).

Mas antes de tal solução, o azmapu privilegia a reparação em vez da punição, nas palavras de um kimche:

"A justiça mapuche era restaurar o que estava perdido, weñegilmi kiñe waka, inatugele ti weñewma then mvley ñi wiñoltuwal ti el, (se eles roubam uma vaca de você, se eles perseguem quem a roubou, então sua obrigação é devolvê-la) como diz a wigka, a espécie, mas eles também têm que pagar a custa, então" (Leucadio Sánchez, em Melin et al, 2016: 42)

É notório que o fato de reparar em vez de punir deve ser apoiado por um forte respeito pela palavra (Melin et al, 2016: 37-40), uma certeza média de que o acordo será cumprido é necessária para que o modelo de resolução de conflitos possa ser seguido pela comunidade.

\section{A FERIDA COLONIAL DO AZMAPU: HISTÓRIA, OLHARES E LINGUAGEM}

A seç̧ão seguinte dá conta de um problema que se explicita a partir da reflexão teórica do giro decolonial, mas que pode encontrar a sua correlação histórica na diversidade dos povos colonizados. Em particular, gostaria de oferecer uma interpretação de como, no território mapuche, a lei e o direito da legislação chilena se tornaram o único e exclusivo relato da normatividade em detrimento de outras tradições e formas ético-normativas. A explicação que pretendo dar procura ir além dos fatores causais óbvios; a invasão militar profissional de um 
território e a imposição inicial das suas instituições. A colonialidade é, em certo sentido, um excesso, que não termina na sua violência original, mas permanece uma ferida aberta na carne ao longo do tempo. Nas palavras de Pablo Marimán, um historiador,

A situação aberta com a derrota levou ao surgimento do fenómeno colonial. Não se trata apenas dos efeitos produzidos pela perda de terras, genocídio, desintegração demográfica (desaparecimento, migração e concentração em reduções) e colonização com a população chilena e estrangeira, mas da reprodução da institucionalidade de um Estado nacional com a missão aberta de conquistar e ocupar todos os espaços: físicos, econômicos e espirituais (Mariman, 2019: 184).

Nesta linha estava também a azmapu - como forma de conhecimento e como prática - um espaço a ser conquistado pela nova institucionalidade que veio com a ocupação militar (início dos anos 1880) e a fundação dos povos, que por sua vez correspondia à legalização da redução do território (1883-1927).

Mantenho em primeiro lugar que a diferença colonial entre azmapu e direita ocidental é fruto deste processo histórico onde "as experiências do colonialismo e da colonialidade com as necessidades do capitalismo, foram configuradas como um novo universo de relações intersubjetivas de dominação" (Quijano, 2007: 94). Esta relação intersubjetiva de dominação que Quijano chama de "modernidade", toma forma em Wallmapu através de formas de representação e valorização; o visível e o legítimo tornam-se então um centro e um acima, ou nas palavras de José Quidel, "somente o poder dos wigka, suas ideias, têm peso e são valorizadas, são o centro dos acontecimentos, enquanto tudo relacionado ao mapuche az mogen foi escondido outro tanto, perdeu toda a legitimidade e tornou-se invisível” (Quidel, 2015: 42).

Esta perda de legitimidade, segundo o que proponho, é determinada por uma forma de ordenação própria da modernidade/colonialidade; a das hierarquias verticais. No seu capítulo "Sobre a colonialidade do ser: contribuições para o desenvolvimento de um conceito" Maldonado-Torres faz uma análise aguda de como as categorias de dominação foram definidas por meio da racialização da conquista e da colônia:

"Uma característica deste tipo de classificação social é que a relação entre os sujeitos não é horizontal, mas vertical. Ou seja, algumas identidades denotam superioridade sobre outras. E tal grau de superioridade é justificado em relação aos graus de humanidade atribuídos às identidades em questão. Em termos gerais, quanto mais clara for a pele, mais perto está de representar o ideal da humanidade completa. Na visão dos conquistadores, serviu para criar novos mapas do mundo; a geografia continuou a produzir 
esta visão das coisas. O mundo inteiro foi visto à luz desta lógica” (Maldonado-Torres, 2007: 132).

Penso que a classificação ontológica proposta pelo MaldonadoTorres é extensiva também à esfera normativa. Ao contrário da lei ocidental, institucionalizada em estruturas hierárquicas e verticalmente dependentes umas das outras, o azmapu foi tecido a partir do pensamento mapuche como um tipo de ordem orgânica, onde a dimensão horizontal da solução é mais consistente do que um mandato vertical. Em seu estudo sobre antropologia legal e sistemas de sanções, Villegas indicou sobre o desempenho da logko (autoridade tradicional reconhecida no povo mapuche) em casos de justiça:

Poucas ocasiões existem atualmente em que um terceiro intervenha na solução do conflito, geralmente o lonko, ou alguma outra pessoa ou pessoas que são reconhecidas como autoridades dentro da comunidade, e quando o faz, parece tomar a forma de um compositor amigável e não de um juiz (Villegas, 2014: 231).

A diferença entre esta forma orgânica de ordenar o certo e o errado (como alguém ordenando os elementos de uma casa ou barracão) e a forma vertical de "ordenar" como um comando, é, na minha opinião, também uma diferença na forma de observar e conhecer. Como sugeri na primeira seção deste trabalho, a forma de olhar no azmapu é um tipo de observação não hierárquica (a partir do parâmetro antropocêntrico). Em certo sentido, a diferença de abordagem corresponde à intuição de Castro-Gomez, que indica que o sujeito moderno "não consegue obter um olhar orgânico sobre o mundo, mas apenas um olhar analítico" (Castro-Gomez, 2007: 83). A lei que começa a operar no território mapuche com a chegada e usurpação do Estado chileno representa as condutas, transgressões e soluções, do ponto de vista analítico; por seu sucesso e desempenho, empresta então uma linguagem normativa dos códigos legais europeus. Desta forma "princípio da proporcionalidade", "princípio da legalidade", "culpa", "castigo" são constituídos numa linguagem (aparentemente) com sentido; categorias que apoiadas no uso da força - têm um efeito no mundo, nas condutas e nas relações intersubjetivas das comunidades humanas que se pretende comandar e governar. Seguindo novamente o P. Mariman:

Neste contexto, as estruturas de governança, a antiga Wichanmapu, deixaram de ser funcionais e com ela a autoridade do grande longko declinou. A influência destes no nível de redução foi relativizada e diminuiu consideravelmente, de modo que seu papel de condutor e regulador de conflitos diários da comunidade foi substituído por outros órgãos e agentes, como os Protetores de Indígenas e depois os Tribunais de Índios, que atenderam os membros da comunidade em litígio para garantir um espaço mínimo para sua sobrevivência (Mariman, 2019: 179). 
Acontece então que a própria linguagem do azmapu; gülam, conselho;yam, respeito; az mogen, imagem ou ordem da vida; ngen, dono do espaço, permanece tão significativa de um olhar orgânico no pensamento mapuche, enquanto a nova linguagem excludente e informática do real permanece como olhar analítico. Esta última linguagem é funcional, particular e delimita continuamente o externo e o interno, porque apenas o que é delimitado ou "próximo" é susceptível de ser dominado e, portanto, apropriado. O primeiro, por outro lado, é constantemente um excesso, mas um excesso diferente do da ferida colonial, é um excesso que "quebra o princípio da semelhança" (De la Cadena, 2017), onde as palavras que designam ngülam, az mogen, significam sempre mais do que a tradução sugere, e no caso do ngen (dono de um espaço) coloca-nos perante a diferença de compreensão ontológica ${ }^{4}$ do território e dos seus elementos.

Explico, ao olhar analítico que cerca e limita os elementos de um território - por exemplo um rio - o curso de água é apresentado apenas como um possível recurso de exploração e quantitativamente valorizável de acordo com um preço. Seguindo Laval e Dardot, esta medida facilita a comunicação de informações, pois "o preço é um meio de comunicação de informações através do qual os indivíduos podem coordenar suas ações" (Laval \& Dardot, 2013: 145). No entanto, e aqui está o imensurável das visões levantadas, a informação do olhar analítico é uma realização parcial em vista do objetivo humano de domínio no contexto neoliberal. Pensar, em vez disso, no rio como ngen, supõe um excesso de informação alheia ao preço, é relacionar-se reciprocamente com o espaço territorial como um vivente para quem o diálogo e a palavra são possíveis. Este é também um sentido possível para a azmapu, além do já indicado como uma forma de direito próprio:

Dentro de um território há outros $A z M a p u$ de espaços menores, que compõem o AzMapu de uma área, com as pessoas que se identificam com ele e suas características geográficas: territórios de terra plana, com ou sem a presença de plantas nativas, com a presença de certas aves e animais nativos, a cor do solo (Melin et al, 2016:21)

Nesta forma de relacionar-se, o homem e a mulher Mapuche que transitam a história divergem do sujeito moderno explicado por Castro-Gomez. $\mathrm{Na}$ verdade, o sujeito moderno, diz o autor, tenta se situar no olhar orgânico do Deus Absconditus (Casto-Gómez, 2007) mas sem alcançá-lo, ou seja, tenta colocar a si e a sua razão ilustrada no lugar não observado de onde tudo se observa ${ }^{5}$. Tal substituição de lugar não seria possível a partir de um olhar mapuche; já que não existe um lugar de primazia para um deus único e onipresente a quem substituir, mas diversos newen, ngünen, ngen. A pretensão pela qual o sujeito moderno (provincial e europeu) trata de obter um olhar total frustrado é talvez pensada a partir deste "outro" modo de agir e de saber.

Voltando à reflexão sobre como a lei ocidental acaba sendo o único direito possível, penso que um estudo necessário é o das instituições estatais que foram 
configuradas após a conquista, especialmente a figura do Protetor de Indígenas, do Tribunal de Índios e a do juiz de campo ${ }^{7}$. Esta última, sendo uma instituição da colônia sob a monarquia espanhola, teve alguma continuação na era republicana, por extensão e cuidado deixo pendente a análise destas instituições, sendo que uma abordagem do assunto pode ser consultada nas fontes a seguir mencionadas.

\section{CONCLUSÕES}

Abordar a noção de azmapu a partir das reflexões da colonialidade e da modernidade permite uma abordagem diferente da antropologia legal. Embora a antropologia jurídica e as discussões sobre o pluralismo jurídico - como as utilizadas pelos textos que orientaram a primeira seção - sirvam para situar a categoria e dar-lhe um possível conteúdo de crítica, é a análise históricoconceitual que nos permite entrar nas maiores tensões que um pensamento outro, uma norma diversa e divergente, pode gerar ao atual modelo de conhecimento e sanção que se vê a si mesmo como único e dominante.

Pensar azmapu desde sua colonialidade do ser e do saber permite-nos compreender, por um lado, como o direito ocidental se constitui como poder, e, por outro, trazer para a frente da trama os lugares (materiais e não materiais) onde o pensamento indígena deste determinado território ainda pode explodir e desafiar. Sobre este último, acredito que o caso dos elementos naturais, sua exploração como recursos pelo neoliberalismo corrigido e a correspondente defesa dos espaços pelas comunidades é o ponto de maior confrontação, tanto na prática como na disputa sobre o que a lei e as normas podem significar.

A diferença colonial no ponto de vista de um sistema e de outro parece ser o fator decisivo neste momento. A metáfora sobre a visão do sujeito moderno postulada por Castro-Gomez é, neste campo, especialmente fecunda, permitenos compreender que não só o conhecimento pode ser construído a partir deste hipotético - mas realmente nunca realizável - ponto de vista mas outras formas de dominação - como a lei e sua pretensão sobre a ordenação da vida podem ser localizadas a partir desta fantasia de poder e delimitação. Narrar a diferença, investigando a natureza da forma que foi levantada como poderosa, contribui igualmente para quebrar esses limites, para repensar o conhecimento que tinha sido excluído e para compreender as suas condições históricas e conceituais.

A preocupação de instalar e aprofundar esta última tensão permanece em aberto. Creio que situar-se no problema responderia à exigência de evitar "um particularismo estreito e fechado que conduza a um provincialismo ou a um fundamentalismo segregacionista, murado na sua particularidade" (Grosfoguel, 2007: 72); do meu ponto de vista é no contexto de emergência onde pensar o Mapuche e a sua ideia de justiça seria pensar também em como este conhecimento localizado se abre a uma experiência transfronteiriça e a um diálogo horizontal, contribuindo da sua especificidade para os problemas e experiências de outras comunidades e latitudes. 


\section{NOTAS}

1 Uma versão em espanhol deste texto foi publicada na Revista de Administración Pública y Sociedad (APyS-IIFAP-FCS-UNC), No 08, Julio-Diciembre 2019 - ISSN: 2524-9568.

2 Visita do então presidente do Chile, Ricardo Lagos, a Alto Bío Bío no contexto do conflito pela construção da central hidrelétrica Ralco operada pela empresa chinesa ENDES no território mapuche-pewenche, 20 de agosto de 2000 (Araya, 2001: 35; Moraga, J., 2001).

3 "Pedir permissão" é um costume extenso que se refere ao momento de ingressar a um novo espaço natural, geralmente para coletar ou dele tomar algo. O pedido de permissão é acompanhado de "saudar" e "agradecer". Também é usual realizar uma ação similar ao tomar a vida de uma árvore ou de um animal do entorno de onde se vive habitualmente.

4 Neste aspecto reflito a partir do monumental trabalho da antropóloga Mercedes de la Cadena. Ver: Earth beings. Ecologies of practice across de Andean worlds (2015).

5 Uma aproximação detalhada à relação entre os fenômenos de secularização e modernidade pode ser encontrada nos capítulos "Modernidad y secularización” e "Una segunda secularización: la crisis de la razón" de Gabriel Amengual (1993), em Estudiar la religión, materiales para una filosofía de la religión III.

6 Ver: "El abogado de los indios y la constitución de la propiedad austral en Chile. Relevancia sociojurídica pasada y presente en las cartas del padre Sigifredo de Fraunhäusl”, Fabian Le Bonniec \& Marcelo Berho Castillo (2018), en Expoliación y violación de los derechos humanos en territorio mapunche.

7 Ver: "La institución del Juez de campo en el reino de Chile durante el siglo XVIII”, María teresa Cobos (1980), en Revista de Estudios Histórico-Jurídicos.

\section{REFERÊNCIAS}

AMENGUAL, G.. Una segunda secularización: la crisis de la razón. En GÓMEZ CAFFARENA, J.; MARDONES, J. M.. Estudiar la religión: materiales para una filosofía de la religión III. Barcelona: Anthropos, 1993.

CANIULLAN COLIÑIR, V., \& MELLICO AVENDAÑO, F.. Mapuche lawentuwün. Formas de medicina mapuche. En BECERRA, R.; LLANQUINAO, G.. Mapun kimün. Relaciones mapunche entre persona, tiempo y espacio. Santiago de Chile: Ocho Libros Editores, 2017, p. 41-79.

CASTRO-GÓMEZ, S.. Decolonizar la universidad. La hybris del punto cero. En CASTRO-GÓMEZ, S.; GROSFOGUEL, R.. El giro decolonial. Bogotá: Siglo del Hombre, 2007, p. 79-91.

COBOS, M. T.. La institución del Juez de campo en el reino de Chile durante el siglo XVIII. Revista de Estudios Histórico-Jurídicos. Valparaiso, v. 5, 1980, 85-165.

DE LA CADENA, M.. Earth Beigns. Ecologies of practice across Andean worlds. London: Duke University Press, 2015. 
DE LA CADENA, M.. Cuando la naturaleza no es común... o protestas desde lo incomún (Conferencia). Santiago de Chile: Clase inaugural del año académico 2017. Programa de Antropología, Pontificia Universidad Católica de Temuco. 2017.

DUSSEL, E.. Modernity, Eurocentrism, and Trans-Modernity: In Dialogue with Charles Taylor. En E. M. (ed.), The Underside of Modernity:. Atlantic Highlands: Humanities, 1996.

GROSFOGUEL, R.. Descolonizando los universalismos occidentales: el pluri-versalismo transmoderno decolonial desde Aimé Cesaire hasta los zapatistas. En CASTROGÓMEZ, S.; \& GROSFOGUEL, R.. El giro decolonial. Bogotá: Siglo del Hombre, 2007, p. 63-77.

HUNCHUNAO, J.. Los mapuche: el pueblo que lucha para reconstruirse. Le Monde Diplomatique, Octubre 2016, p. 5-6.

LAVAL, C., \& DARDOT, P.. La nueva razón del mundo. Barcelona: Gedisa, 2013.

LE BONNIEC, F., \& BERHO CASTILLO, M.. El abogado de los indios y la constitución de la propiedad austral en Chile. Relevancia sociojurídica pasada y presente en las cartas del padre Sigifredo de Fraunhäusl. En POZO, G.. Expoliación y vioalción de los derechos humanos en territorio mapunche. Santiago de Chile: Ocho Libros, 2018, p. 435-451.

MALDONADO-TORRES, N.. Sobre la colonialidad del ser: contribuciones al desarrollo. En CASTRO-GÓMEZ, S.; GROSFOGUEL, R.. El giro decolonial. Bogotá: Siglo del Hombre Editores, 2007, p. 127-167.

MARIMAN, P.. Los mapuche antes de la conquista militar chileno-argentina. En MARIMAN, P.; NAHUELQUIR, F.; MILLALEN, J.; CALFIO, M.; LEVIL, R.. jAllkütunge wingka! jka kiñechi! Ensayos sobre historias mapuche. Temuco: Ediciones Comunidad de Historia Mapuche, 2019, p. 77-192.

MELIN, M.; COLIQUEO, P.; CURIHUINCA, E.; ROYO, M.. Azmapu. Una Aproximación al Sistema Normativo Mapuche desde el Rakizuam y el Derecho Propio. Territorio Mapuche: INDH, 2016.

MIGNOLO, W.. El pensamiento decolonial: desprendimiento y apertura. En S. CastroGómez, \& R. Grosfoguel, El giro decolonial (págs. 25-46). Bogotá: Siglo del hombre Editores, 2007, p. 25-46.

MORAGA, J.. Aguas turbias. La central Ralco en el Alto Bío Bío. Santiago: Observatorio Latinoamericano de Conflictos Ambientales, 2001.

QUIDEL, J.. Chumgelu ka chumgechi pu mapuche ñi kuxankagepan ka hotukagepan ñi rakizuam ka ñi püjü zugu mew. En MAPUCHE, C. D.. Awükan ka kuxankan zugu Wajmapu mew. Violencias coloniales en Wajmapu. Temuco: Ediciones Comunidad de Historia Mapuche, 2015, p. 21-56. 
QUIJANO , A.. Colonialidad del poder y clasifi cación social. En CASTRO-GÓMEZ, S.; GROSFOGUEL, R.. El giro decolonial. Bogotá: Siglo del Hombre, 2007, p. 93-126.

TORO, A. (Dirección). Berta y Nicolasa, las hermanas Quintreman [Película], 2002.

VILLEGAS, Myrna. "Sistemas sancionatorios indígenas y Derecho penal. ¿Subsiste el Az Mapu?”. Política Criminal, Talca, vol. 9, no 17 (Julio 2014), Art. 7, pp. 213-247.

Submetido: $28 / 03 / 2020$

Aceito: $15 / 04 / 2020$ 


\section{AZMAPU: UMA PROPOSTA NORMATIVA MAPUCHE}

\section{Resumo}

$\mathrm{O}$ artigo seguinte destaca elementos de interesse a fim de abordar uma proposta normativa da maneira de pensar do povo Mapuche. Com base em trabalhos recentemente publicados sobre o assunto, define-se o significado de azmapu, uma forma de regulação própria e diferente da lei positiva. Além disso, o trabalho elabora, a partir das teorias do giro decolonial, uma explicação das diferenças conceituais e ontológicas entre a forma da lei azmapu e a lei ocidental.

Palavra-chave: Pluralismo legal. Lei indígena. Mapuche. Giro decolonial. Filosofia da lei. 


\title{
AZMAPU: A MAPUCHE REGULATORY PROPOSAL
}

\begin{abstract}
The article remark topics of interest approaching to a regulatory proposal from the thought of Mapuche people. Since recent published papers the article define the meaning of azmapu, an autonomous law different from positive right. Furthermore, since decolonial turn perspectives, the article intend an explanation on the conceptual and ontological differences between azmapu and the westernized way of right.
\end{abstract}

Keywords: Legal pluralism. Indigenous law. Mapuche. Décolonial turn. Philosophy of law. 